\title{
Investigation of Harmful Chemical Compounds from Dual-Fuelled Diesel Engine
}

\author{
Ruslans Smigins ${ }^{1 *}$, Tomasz Skrzek², Milena Górska ${ }^{3}$, Grzegorz Pawlak ${ }^{4}$ \\ 1 Latvia University of Life Sciences and Technologies, J. Cakstes blvd 5, Jelgava, LV3001 Latvia \\ 2 Faculty of Mechanical Engineering, Kazimierz Pulaski University of Technology and Humanities in Radom, \\ ul. Chrobrego 45, 26-200 Radom, Poland \\ ${ }^{3}$ Faculty of Material Science, Technology and Design, Kazimierz Pulaski University of Technology and \\ Humanities in Radom, Radom, Poland \\ ${ }^{4}$ Military Institute of Automotive and Armor Technology, Okuniewska 1, 05-070 Sulejówek, Poland \\ * Corresponding author's e-mail: ruslans.smigins@llu.Iv
}

\begin{abstract}
This paper investigated the impact of the exhaust gas recirculation on the concentration of selected harmful chemical compounds from the AVL 5402 research diesel engine powered with diesel fuel (DF) and compressed natural gas $(\mathrm{CNG})$. The engine was operated in the dual fuel mode. It means that the engine was conventionally fuelled by regular diesel fuel and simultaneously by $\mathrm{CNG}$ dosed into the inlet pipe. The necessary tests were carried out for the mixtures containing 30, 50 and $70 \%$ of $\mathrm{CNG}$ (by energy content) in the total chemical energy delivered together with diesel fuel (DF) into the combustion chamber. The research was conducted for the stationary conditions of the engine operation at $1200 \mathrm{rpm}$ and constant 1004 Joules of a fuel chemical energy delivered in each cycle into the combustion chamber. Under such conditions, the impact of the EGR rate changed in range of 0-50\% on the emissions of selected unburned hydrocarbons (HC), carbon monoxide (CO), nitrogen oxides (NOx) as well as particulate matter (PM), was evaluated. The obtained results confirmed that the EGR system is effective in the reduction of the NOx formation for all tested fuel mixtures. Nevertheless, it was found that the addition of CNG combusted in the diesel engine generates more harmful pollutants in comparison with diesel fuel. However, in some cases the concentration of NOx as well as PM was comparable or lower. It suggests that the combustion of CNG in diesels allows achieving environmental benefits. In this case, further optimization of the engine fuel supply system is necessary.
\end{abstract}

Keywords: diesel engine; $\mathrm{CNG}$; harmful emissions, alternative fuel.

\section{INTRODUCTION}

Due the environmental challenges, new fuels for internal combustion (IC) engines are still being developed. A lot of studies are focused on renewable fuels such as biodiesel, selected alcohols (ethanol, methanol) as well as plant oils and their mixtures with n-hexane [13]. Additionally, selected ethers, including ethyl tert-butyl ether [7] and diethyl ether, are considered as possible fuels for diesel engines [6, 8]. Thus, gaseous fuels such a liquid natural gas (LNG) as well as a compressed natural gas $(\mathrm{CNG})$ are considered as another alternative fuel for diesel engines. It should be pointed out that the octane number of natural gas $(110 / 130)$ is higher than for regular gasoline (95/98) [9]. For this reason, CNG is applied mainly for the urban vehicles equipped with spark ignition engines. However, lower price of $\mathrm{CNG}$ encourages searching for other possibilities i.e. application of this gaseous fuel also for diesel engines. It is known that the physicochemical properties of CNG are not the best for diesels. As mentioned above, $\mathrm{CNG}$ has a gaseous form and cetane number near to zero. Additionally, the auto-ignition temperature of $\mathrm{CNG}$ is about 
3 times higher, in comparison with regular diesel fuel [10]. These selected factors promote the knocking phenomenon, which can even destroy the engine $[5,12]$. The application of $\mathrm{CNG}$ as a fuel for diesels is limited due to technical barriers. In particular, CNG cannot be delivered into the combustion chamber by the conventional fuel supply system of diesel engines. However, it can be combusted in the diesel engine equipped with a dual fuel system. In such engines, the homogeneous natural gas-air mixture is formed in the engine intake manifold or intake channels and, during the compression stroke, it is ignited by the diesel fuel dose injected into the combustion chamber. The examples of these technologies are well-known and were presented in numerous papers $[2,18]$. On the other hand, there are many problems related with the emissions of harmful gases from dual-fuel diesels, which should be still investigated. They are mainly caused by the complexity of the mixture formation and the process of combustion that is much more difficult to control in comparison with the combustion of regular diesel fuel in a standard diesel engine. The impact of the EGR ratio on the emissions of harmful gases such as nitrogen oxides (NOx) and particulate matter (PM) should be additionally investigated. For a dual fuel mixture consisting of diesel oil and natural gas, the emission of $\mathrm{NO}_{\mathrm{x}}$ increases along with the share of natural gas in the dual fuel mixture [11]. Limited control over the combustion of the dual fuel mixture leads to a higher temperature of the flame front and consequently, correspondingly higher $\mathrm{NO}_{\mathrm{x}}$ emission. Hence, if second fuel is applied (e.g. natural gas provided into the intake channel), which modifies the mechanism of combustion, the use of EGR must be carefully examined and properly controlled.

\section{COMBUSTION IN DUAL FUELLING DIESEL ENGINE}

The combustion process of a dual fuel mixture depends on the engine design features such as the compression ratio [3], the shape of the combustion chamber [16] and the ways how fuels are fed to the engine [26]. Usually, a homogeneous mixture (e.g. natural gas/air mixture) is formed outside the cylinders and ignited by the directly injected diesel fuel. In that case, the combustion process could be controlled by many adjustment parameters, strictly optimized for the engine load and speed:

- injection timing of diesel fuel,

- injection pressure of diesel fuel,

- number of diesel fuel injections per cycle,

- amount of diesel fuel injected per cycle (diesel fuel-air mixture composition),

- amount of natural gas supplied per cycle (natural gas-air mixture composition),

- amount of intake air, its temperature and pressure,

- rate and temperature of EGR.

The complexity of the combustion control process of a dual fuel mixture in a diesel engine, particularly the ignition of a homogeneous mixture by a diesel fuel pilot dose and its results were examined and widely described in literature. Because of its significance, many researchers studied the effects of injection timing on the engine performance and its exhaust emissions [21]. For this type of fuelling, it is crucial to reduce the heat release rate and, consequently, maintain the incylinder pressure rise rate $(d p / d a)$ under the diesel knock limit [20]. Selim [27] investigated a Ricardo diesel engine powered with the mixtures of diesel fuel and CNG. The author confirmed that the increase of the EGR ratio reduces the pressure rise rate. However, 5\% EGR ratio should not be exceeded because the engine efficiency was reduced. Additionally, Tomita et al. [23] investigated the impact of EGR on the emission characteristics and efficiency of diesel engine powered with CNG and diesel fuel. The authors performed several tests on a single cylinder engine that enabled the observation of dual fuel combustion. They observed that the luminous intensity and flame decreased with the increasing EGR rate. Furthermore, the ignition delay became longer (EGR); hence, it influenced the self-ignition mechanism, crucial for the flame propagation and its results. Tomita et al. concluded that the reduction of the nitrogen oxides emission is possible for the selected EGR ratio as well as for proper setting of the diesel fuel injection timing. Similar problems were investigated by Carluci et al. [4]. In particular, the effect of multiple fuel injection on the combustion of the CNG-diesel fuel mixtures was examined. The results confirmed that for small additions of CNG in the fuel mixture i.e. up to $30 \%$ by energy content, a lower emission of soot and oxides was achieved. However, the emissions of unburned hydrocarbons from the 
tested engine was higher. On the other hand, Ogawa et al. [17] stated that high EGR rate applied in a dual fuel compressed ignition (CI) engine does not improve the engine performance at part loads but EGR, combined with pre-heating of the intake air, can slightly increase the thermal efficiency of the engine and reduce the emissions of unburned hydrocarbons, $\mathrm{NO}_{\mathrm{x}}$ and $\mathrm{CO}$. An innovative three stage combustion strategy known as PREMIER (PREmixed Mixture Ignition in the End-gas Region) of CNG-diesel fuel mixture was examined by Azimov et al. [1]. In this system, the combustion is divided into three stages: the first - rapid combustion of diesel fuel and the entrainment of the natural gas mixture in the diesel fuel spray; the second - mild combustion with flame propagation of the natural gas mixture; and the third rapid combustion. The system examined by Azimov allowed increasing the engine efficiency even by $25 \%$, in comparison with the traditional combustion process. Moreover, lower emissions of unburned hydrocarbons and carbon monoxide was reported. However, the emissions of nitrogen oxides was higher.

A very promising dual-fuel strategy that yields good results, especially for the low and medium loads, is the Reactivity Controlled Compression Ignition (RCCI) concept, utilizing premixed gasoline or natural gas. The concept involves a direct injection of diesel fuel to stratify both the equivalence ratio and fuel reactivity, thus allowing greater control over the timing and duration of the heat release. The details of the RCCI system were reported in numerous papers $[15,19,24]$. RCCI is a low-temperature combustion strategy that utilizes early diesel fuel injection necessary for creating a reactivity gradient leading to a staged auto-ignition, in particular from the highest reactivity region to the lowest. The simulations utilizing both early and late direct injection of diesel fuel showed that at high load, the RCCI process is very sensitive to the EGR ratio. For the RCCI concept and all of the above-mentioned combustion strategies realized with the use of two fuels in a CI engine, the injection parameters and the EGR rate are crucial for the engine performance and exhaust emissions.

In the case of the $\mathrm{NO}_{\mathrm{x}}$ and $\mathrm{PM}$ emissions, the relationship between the fuel proportions, the EGR rate and the engine exhaust emissions is very interesting from the practical point of view. The possibility of reducing the two hazardous exhaust emission components by controlling the proportion of fuels and the EGR ratio along with adapting the injection timing of the pilot diesel fuel dose could reduce the application of very complex aftertreatment systems commonly used in the vehicles equipped with $\mathrm{CI}$ engines.

Creation of different dual fuelling concepts of a diesel engine and the development of efficient dual fuel systems is possible owing to new technologies of engine control, especially the development of the common rail system and gas injection systems. New technologies, including strict control of the EGR rate, enable a modification of the complex process of dual fuel mixture combustion to ensure high engine performance together with an acceptable base $\mathrm{NO}_{\mathrm{x}}$ and $\mathrm{PM}$ emissions as well as smooth engine operation. Taking this into account, the impact of the EGR rate on the emissions of harmful gases from diesel engine should be still investigated. This time, the necessary studies were carried out on the AVL research engine powered with the mixtures of diesel fuel and CNG.

\section{MATERIALS AND METHODS}

The experiment was focused on the modification of the dual fuel combustion process of natural gas and diesel fuel through different rate of EGR in order to achieve the lowest possible base engine exhaust emissions, particularly $\mathrm{NO}_{\mathrm{x}}$ and $\mathrm{PM}$, high thermal engine efficiency and a smooth engine operation. The test was carried out on the AVL research engine fitted with the EGR system. The fundamental technical details of the tested engine are listed in Table 1.

A schematic diagram of the test setup used in this study is shown in Figure 1. The test bench was equipped with the AVL i60 FT and the AVL Micro Soot Sensor, which were necessary for the measurement of harmful gases and soot particles,

Table 1. Technical specification of the AVL 4502 engine

\begin{tabular}{|l|l|}
\hline Model & AVL 5402 \\
\hline Fuel supply system & Common Rail \\
\hline Number of cylinders & 1 \\
\hline Displacement $\left[\mathrm{cm}^{3}\right]$ & 511 \\
\hline Bore / stroke [mm] & $85.01 / 90.00$ \\
\hline Cycle & Four stroke \\
\hline Compression ratio & 17.5 \\
\hline Maximum power $[\mathrm{kW}]$ & ca.16 \\
\hline Maximum speed [rpm] & 4200 \\
\hline
\end{tabular}




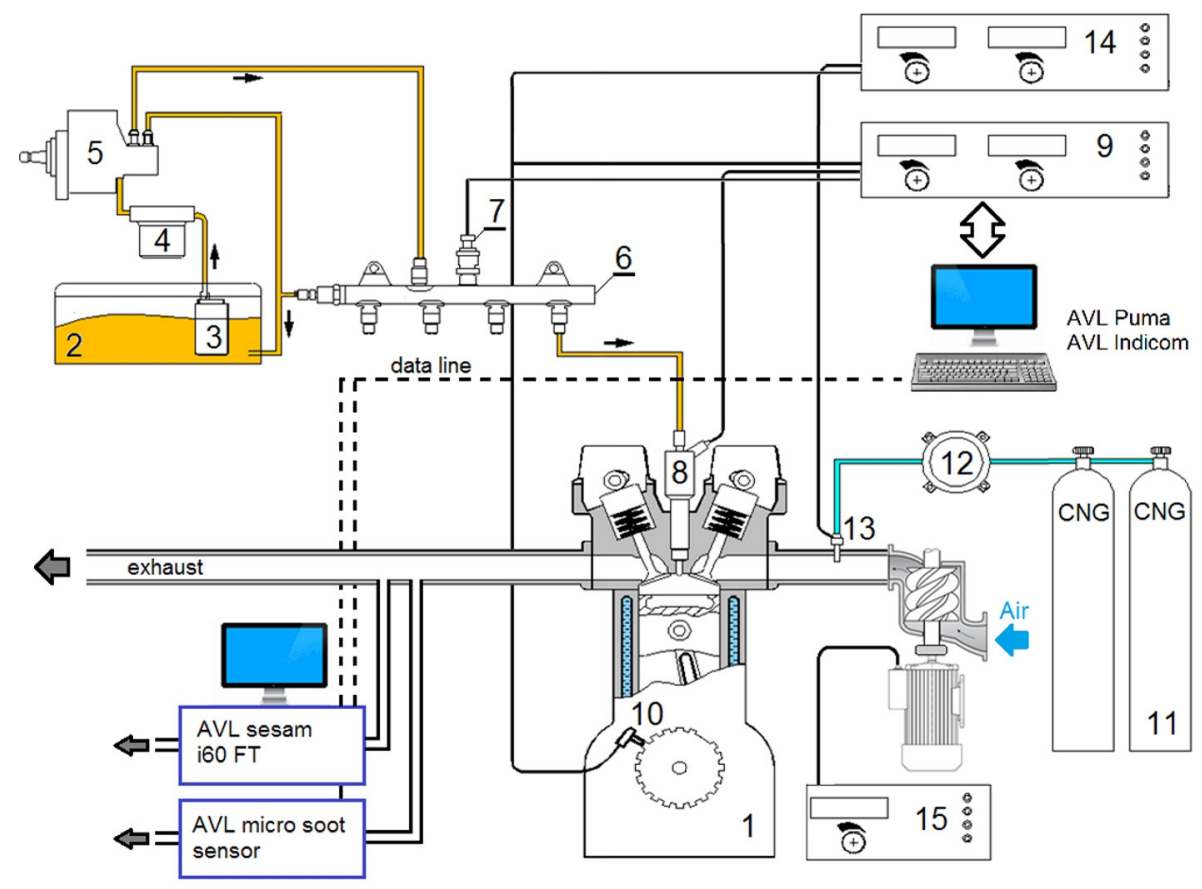

Fig. 1. Scheme of the test setup: 1) the AVL engine, 2) diesel fuel tank, 3) low pressure fuel pump, 4) fuel filter, 5) high-pressure fuel pump, 6) common rail, 7) fuel pressure sensor, 8) diesel fuel injector, 9) common rail controller, 10) crankshaft position and speed sensor, 11) CNG tank, 12) gas pressure reducer, 13) gas injector, 14) gas supply controller, 15) boost control system

respectively. The concentrations of nitrogen oxides, carbon monoxide and unburned hydrocarbons were measured in three repetitions.

The CNG port injection system used in the experiment was equipped with a two-stage gas regulator with a water jacket and a gas port fuel injector. The gas injector was synchronized with the crankshaft position, so that the gas injection timing was optimized to reduce the loss of gas occurring during the valve overlap. It is particularly important from the point of view of the hydrocarbon emissions and the overall engine efficiency. It should be pointed out that the mentioned problem of excessive hydrocarbon emissions due to valve overlap can be limited by gas injection directly to the combustion chamber. An example of such concept was presented by Majczak et al. [14].

The modification of the dual fuel combustion process by EGR was carried out for a constant engine speed and constant thermal energy that would have been theoretically produced after burning of natural gas together with diesel fuel or diesel fuel only provided to the engine cylinder per cycle. Three different fuel mixtures of diesel fuel (DF) and natural gas were tested. These mixtures contained 30,50 and $70 \%$ of natural gas (by chemical energy) in the total fuel energy delivered into the combustion chamber. The aforementioned mixtures were denoted as CNG30, CNG50 and CNG70, respectively.

The substitution ratio of natural gas in the gas/diesel fuel mixture was defined as:

$$
\mathrm{E}_{\mathrm{NG}}=\frac{\mathrm{Q}_{\mathrm{NG}} \cdot \mathrm{m}_{\mathrm{NG}}}{\mathrm{Q}_{\mathrm{NG}} \cdot \mathrm{m}_{\mathrm{NG}}+\mathrm{Q}_{\mathrm{DO}} \cdot \mathrm{m}_{\mathrm{DO}}} \cdot 100 \%
$$

where: $Q_{N G}-$ calorific value of natural gas

$m_{N G}-$ dose of natural gas

$Q_{D O}$-calorific value of diesel fuel

$m_{D O}-$ dose of diesel fuel

During the experiment, the boost pressure was kept constant (the research engine is equipped with boost pressure regulation) and a constant diesel fuel injection pressure was set in the rail. The fundamental settings of the engine, which were applied during the tests are listed in Table 2.

During the tests, the temperature of EGR system was controlled and maintained at the same level. As mentioned above, this study evaluates the impact of the EGR ratio on the concentration of selected harmful chemical compounds from the engine fuelled with CNG and diesel fuel. Taking this into account, the EGR ratio was defined as follows:

$$
\mathrm{EGR}=\frac{\dot{\mathrm{m}}_{\mathrm{EGR}}}{\dot{\mathrm{m}}_{\mathrm{a}}+\dot{\mathrm{m}}_{\mathrm{NG}}+\dot{\mathrm{m}}_{\mathrm{EGR}}} \cdot 100 \%
$$


Table 2. Engine settings

\begin{tabular}{|l|c|}
\hline Engine speed [rpm] & 1200 \\
\hline $\begin{array}{l}\text { Substitution ratio of natural gas in gas/diesel } \\
\text { fuel mixture [\%] }\end{array}$ & $30 ; 50 ; 70$ \\
\hline Common rail injection pressure [bar] & 1000 \\
\hline Fuel energy provided per cycle [J] & 1004 \\
\hline Mass of the first diesel fuel dose [mg] & 1.5 \\
\hline Injection timing of the first dose [deg BTDC] & 16 \\
\hline Injection timing of the second dose [deg BTDC] & 1 \\
\hline $\begin{array}{l}\text { Intake temperature of air-natural gas-EGR } \\
\left.\text { mixture [ }{ }^{\circ} \mathrm{C}\right]\end{array}$ & 32 \\
\hline Valve overlap [deg] & 80 \\
\hline Boost pressure [mbar] & 250 \\
\hline
\end{tabular}

where: $m_{E G R}-$ EGR mass flow,

$m_{a}-$ air mass flow,

$m_{N G}-$ natural gas mass flow.

In order to carefully examine the impact of the exhaust gases recirculation on the combustion process of $\mathrm{CNG}$ - diesel fuel mixtures, a wide range $(0-50 \%)$ of the EGR rates was applied.

In order to realize the Premixed Charge Compression Ignition (PCCI) process, two doses of diesel fuel per cycle were applied. The first pilot dose was constant, regardless of the changing energy shares of both fuels (diesel fuel and natural gas) and the second dose depended on the natural gas substitution ratio. Both the injection timing and the quantity of the first pilot dose were selected based on the preliminary studies to obtain the highest thermal efficiency and to reduce the maximum engine pressure with a view to minimize the possibility of hammering. For all the examined conditions, the injection timing of two diesel fuel doses was the same (Table 2). All the results obtained for the EGR application were compared with the initial conditions (fueling with diesel fuel without EGR).

\section{RESULTS AND DISCUSSION}

The results of the measurements related to the engine emission, particularly the volumetric share of $\mathrm{NO}_{\mathrm{x}}$ and $\mathrm{PM}$ in the exhaust gas for the three examined natural gas substitution ratios in the dual fuel mixture, were shown in Figure 2 and 3 , respectively.

A very interesting phenomenon was observed during the tests focused on the nitrogen oxide emissions. As it can be seen in Figure 2, the lowest concentration of NOx was detected for the CNG30 mixture, but it increased along with the natural gas ratio. It confirms that the $\mathrm{CNG}$ addition can reduce the formation of $\mathrm{NOx}$, but it is possible only for an optimal CNG - diesel fuel ratio. Moreover, the experiment confirmed a very positive influence of EGR on the reduction of the $\mathrm{NO}_{\mathrm{x}}$ emission. It is known that the formation of $\mathrm{NO}_{x}$ is very sensitive to the temperature inside the combustion chamber. EGR contributes to the reduction of the oxygen available for combustion. The modification of the combustion process caused by EGR always leads to a reduction of the peak temperature of combustion and in this way, formation $\mathrm{NO}_{2}$ is accordingly limited. The addition of natural gas increases the overall heat capacity of the in-cylinder mixture and the mean temperature at the end of the compression stroke

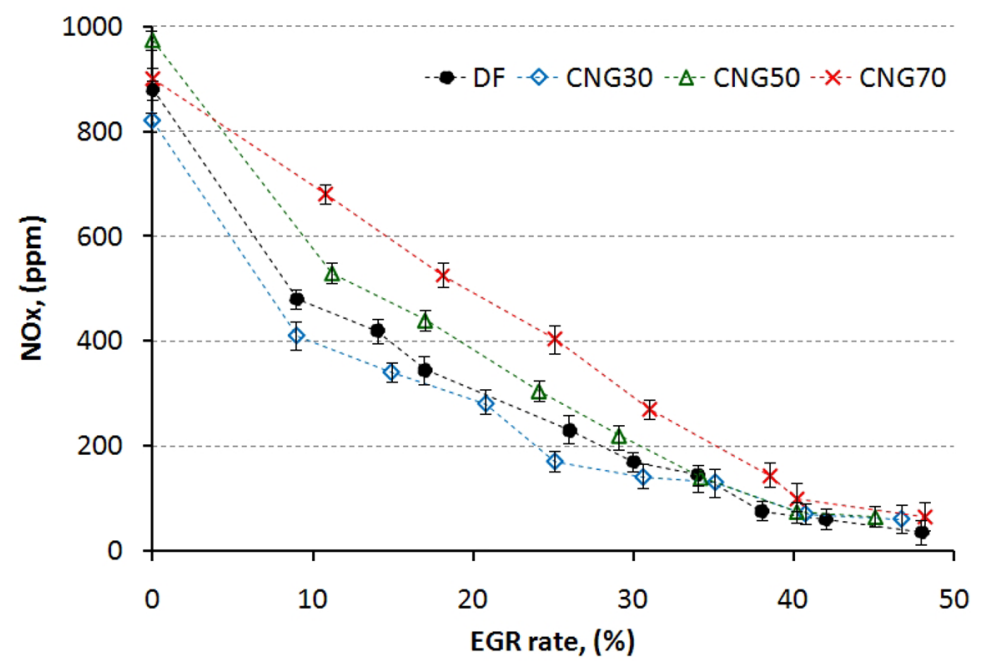

Fig. 2. Impact of the EGR ratio on NOx concentration in the exhaust gas stream of the AVL research engine fuelled with DF-CNG mixtures 


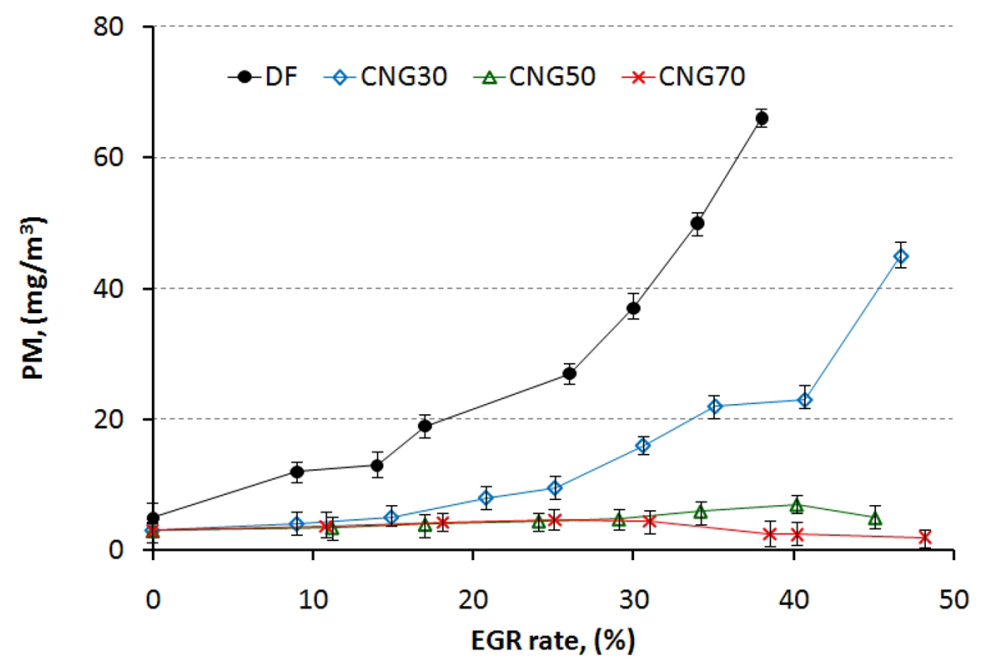

Fig. 3. An impact of the EGR ratio on the PM emission from the AVL research engine fuelled with the DF-CNG mixtures

and during the combustion process is reduced accordingly. Some reports suggest that greater intensity of the heat release in the premixed combustion stage of the dual fuel mixture increases the maximum combustion temperature, causing an increase in the emission of $\mathrm{NO}_{x}[25]$.

In the case of diesel engines, the emissions of soot particles is considered as one of the most important environmental problems. For this reason, different technologies, such as particulate filters are more and more common, not only in diesels, but also in the vehicles equipped with gasoline direct injection engines. Figure 3 confirms that the fuel mixtures containing CNG reduce the emission of particulate matter (PM) significantly.

The experiment confirmed that the increased content of $\mathrm{CNG}$ in the fuel mixture reduced the emissions of PM. Nevertheless, it was confirmed that the EGR system can promote the formation of PM. Figure 3 shows the relationship between the $\mathrm{PM}$ emissions and the EGR rate. It is noteworthy that the PM emissions rapidly increase along with the EGR rate in the dual fuel mixture containing the lowest amounts of natural gas $(30 \%$ substitution ratio), similarly to diesel fuelling. For the higher natural gas substitution ratios $(50 \%$ and $70 \%)$ the $\mathrm{PM}$ emissions are not affected by the EGR ratio.

In this study, the concentration analysis of unburned hydrocarbons was divided into two kinds i.e.: methane $\left(\mathrm{CH}_{4}\right)$ and total unburned hydrocarbons (THC). Dual fuel operation usually leads to a higher concentration of unburned hydrocarbons, mainly due to valve overlap causing a blow of the unburned gas-air mixture out of the cylinder. It is confirmed in Figure 4.
As it can be seen in Figure 4, the concentration of methane increases significantly with higher content of $\mathrm{CNG}$ in a fuel mixture. It should be pointed that $\mathrm{CH}_{4}$ is the main content of the $\mathrm{CNG}$ dosed into the inlet pipe. For this reason, a small part of $\mathrm{CH}_{4}$ is emitted into the air due to valve overlap at the end of exhaust and beginning of intake stroke. On the basis of the research results, it can be stated that the EGR rate does not have a significant impact on the methane concentration in the exhaust gas stream. However, it was found that above $40 \%$ of EGR rate, the concentration of methane slightly increases.

The above-mentioned problem of valve overlap also directly affects the measured concentration of the unburned hydrocarbons. It should be highlighted that THC contains not only unburned hydrocarbons but also raw methane which is the main component of CNG blown by open valves in to the exhaust pipe.

As it can be seen in Figure 5, the concentration of THC significantly depends on the natural gas substitution ratio of the fuel mixture. The increase in the THC concentration is proportional to the natural gas share and increases by approx. $2000 \mathrm{ppm}$ for each $20 \%$ increase in the natural gas substitution ratio of the mixture. The main contribution to the concentration level is the emissions of methane, which indicates that its main source is the fresh charge flow from the intake to the outlet during valve overlap and cylinder scavenging. The valve overlap in the AVL research engine was set to $80 \mathrm{deg}$ (typical value of this type of engine) but as it turned out, it should have been modified and optimized for dual fuel operation. On the 


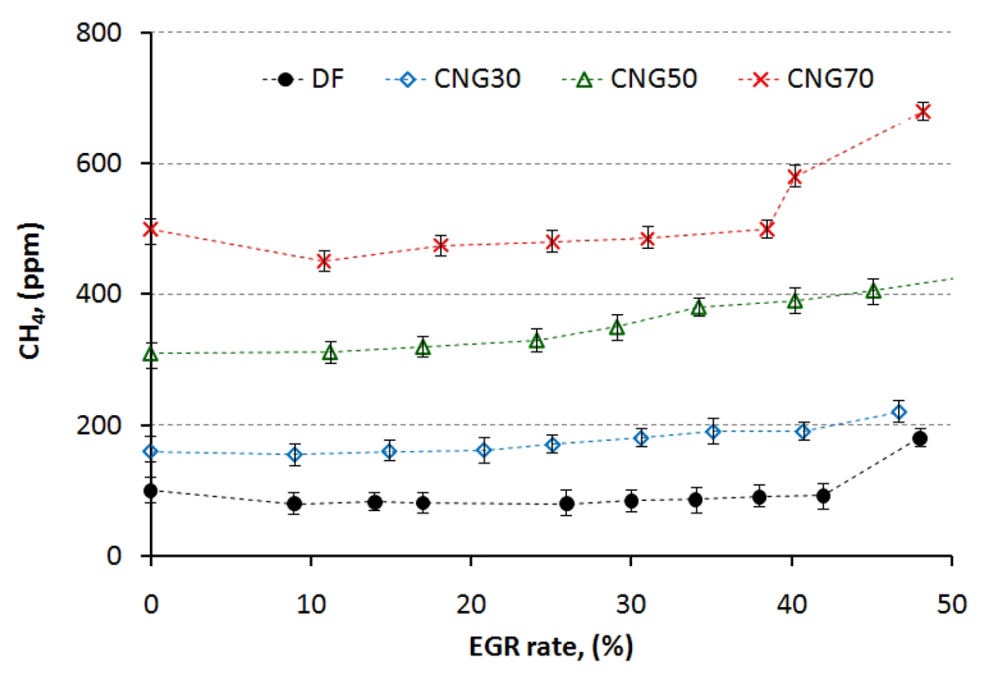

Fig. 4. Concentration of methane $\mathrm{CH}_{4}$ vs. EGR rate for the AVL engine powered with diesel fuel and $\mathrm{CNG}$ - diesel fuel mixtures

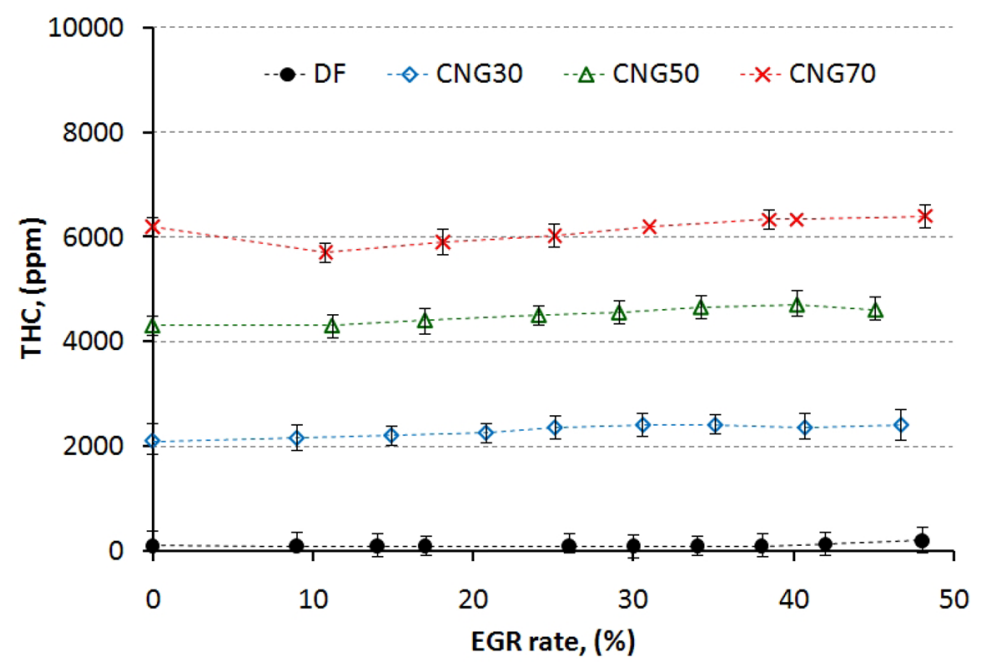

Fig. 5. Concentration of THC vs. EGR rate for the AVL engine powered with diesel fuel and $\mathrm{CNG}$ - diesel fuel mixtures

basis of the research results, it can be stated that the EGR rate does not have an impact on the concentration of THC in exhaust stream gases.

In all three examined cases of the natural gas substitution ratio, it was observed that the nonmethane emission is rising and the increase is approximately directly proportional to the increase in the natural gas share in the fuel mixture.

The presence of natural gas in the air-fuel mixture caused an increase in the $\mathrm{CO}$ emission, but there were no significant differences between the emission of the engine fueled with the lowest and the highest substitution ratios of natural gas in the mixture of fuels. Up to $35 \%$ EGR rate, there was no significant influence of EGR on the emission of $\mathrm{CO}$ for both diesel fuelling and dual fuelling. Figure 6 shows that an excessive amount of EGR caused a sharp increase in the $\mathrm{CO}$ emissions, which was a result of incomplete combustion.

The formation of $\mathrm{CO}$ is associated with the oxygen availability in the combustion chamber. For higher EGR rates (more than 30-35\%) the excess air coefficient $\lambda$ dropped below 1.2-1.25 and, as a consequence, the $\mathrm{CO}$ concentration was adequately higher. From this point of view, there is a limit of EGR rate set at the value close to $40 \%$.

\section{CONCLUSIONS}

The results of the experiment confirmed that the influence of EGR on the combustion process, particularly the combustion of dual fuel mixtures, 


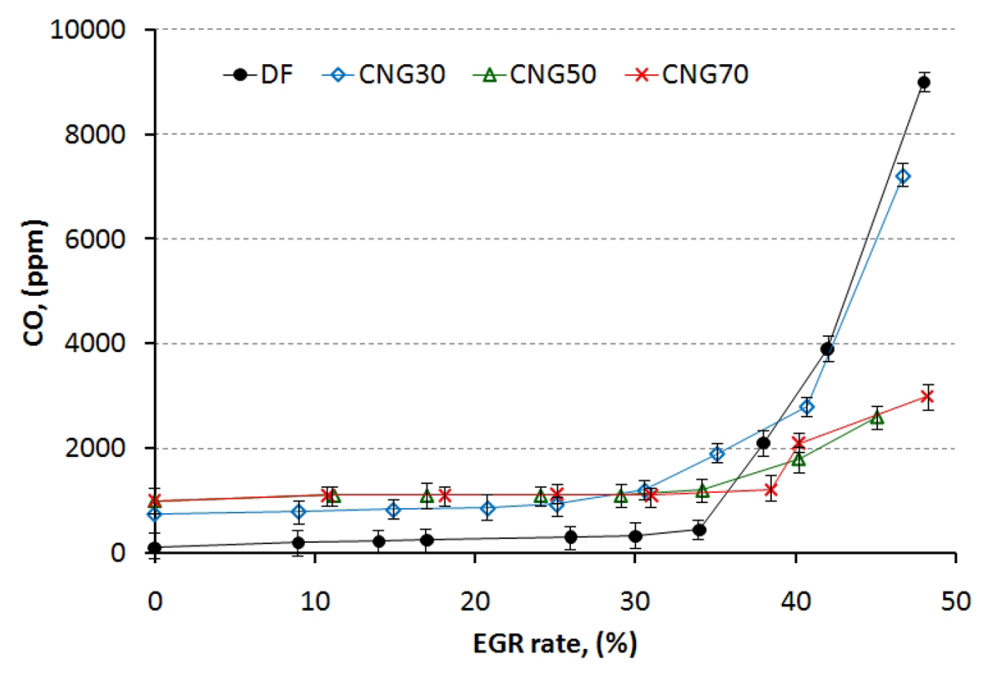

Fig. 6. An impact of the EGR ratio on CO emission from the AVL research engine fuelled with DF-CNG mixtures

is strong and depends on the EGR rate as well as on the natural gas substitution ratio of the fuel mixture. The experiment showed that EGR is a very effective way of controlling the concentration of $\mathrm{NO}_{\mathrm{x}}$ for different dual fuel mixture compositions. A very good effect of the $\mathrm{NO}_{\mathrm{x}}$ reduction with the use of EGR was observed for the dual fuel mixture containing up to $30 \%$ of compressed natural gas. On the basis of our experiences, it can be stated that in this case, the rate of heat release is high but the burning mixture is sufficiently diluted through the application of EGR. Because the amount of diesel fuel injected into a homogeneous mixture diluted through EGR is relatively large, the reduction of the charge temperature near the area of fuel injection could be significant and it could explain the drop of the $\mathrm{NO}_{\mathrm{x}}$ concentration. In the case of higher substitution ratios, the combustion process generates more NOx for all EGR rates.

It was observed that the substitution ratio of natural gas in the mixture heavily affected the PM emissions. Nearly neutral influence of EGR on the emission of PM was observed for higher substitution ratios of compressed natural gas in the dual fuel mixture. In the case of dual fueling with the $30 \%$ compressed natural gas substitution ratio, the increase in the EGR rate caused a significant increase in the emission of PM, particularly for higher EGR rates.

Owing to the application of EGR, it was possible to effectively burn the dual fuel mixtures containing $70 \%$ of CNG. The maximum EGR rate in this case is estimated at $30-35 \%$. A higher EGR rate reduced the amount of oxygen in the mixture and caused an increase in the emission of THC and CO, which should result in a drop of the engine thermal efficiency. The results of the described tests show that the addition of recirculated exhaust gas provides better fuelling flexibility of $\mathrm{CI}$ engines and significantly contributes to solving the problem of reducing the engine exhaust emissions.

\section{REFERENCES}

1. Azimov U., Tomita E., Kawahara N., Harada Y. Premixed mixture ignition in the end-gas region (PREMIER) combustion in a natural gas dual-fuel engine operating range and exhaust emissions. International Journal of Engine Research, 12(5), 2011, 484-497. DOI: 10.1177/1468087411409664

2. Bari S., Hossain S.N. Performance of a diesel engine run on diesel and natural gas in dual-fuel mode of operation. Energy Procedia, 160, 2019, 215-222. DOI: 10.1016/j.egypro.2019.02.139.

3. Bhaskor J., Bora., Ujjwal K., Saha, Soumya, Chatterjee, Vijay Veer. Effect of compression ratio on performance, combustion and emission characteristics of a dual fuel diesel engine run on raw biogas. Energy Conversion and Management, 87, 2014, 1000-1009. DOI: 10.1016/j.enconman.2014.07.080.

4. Carlucci A.P., Ficarella A., Laforgia D. Control of the combustion behavior in a diesel engine using early injection and gas addition. Applied Thermal Engineering, 26(17-18), 2006, 2279-2286, DOI: 10.1016/j.applthermaleng.2006.03.016.

5. Fathul Hakim Zulkifli, Mas Fawzi, Shahrul Azmir Osma. A Review on Knock Phenomena in CNGDiesel Dual Fuel System. Applied Mechanics and Materials, 773-774, 2015, 550-554. DOI: 10.4028/ www.scientific.net/AMM.773-774.550 
6. Górski K., Przedlacki M. Evolution of the influence of Diethy Ether (DEE) addition on selected physicochemical properties of diesel oil and ignition delay period. Energy and Fuels, 28(4), 2014, 2608-2616. DOI: 10.1021/ef4025036

7. Górski K., Sen A.K., Lotkow W., Swat M. Effects of ethyl-tert-butyl ether (ETBE) addition on the physicochemical properties of diesel oil and particulate matter and smoke emissions from diesel engines. Fuel, 103, 2013, 1138-1143. DOI: 10.1016/j.fuel.2012.09.004

8. Górski K., Smigins R. Selected physicochemical properties of diethyl ether/rapeseed oil blends and their impact on diesel engine smoke opacity. Energy Fuels, 32(2), 2018, 1796-1803. DOI: 10.1021/ acs.energyfuels. $7 \mathrm{~b} 03225$

9. Chala G.T., Abd Aziz A.R., Hagos F.Y. Natural Gas Engine Technologies: Challenges and Energy Sustainability Issue. Energies, 11(11), 2018, DOI: 10.3390/en11112934

10. Jamrozik A., Tutak W., Grab-Rogaliński K. An Experimental Study on the Performance and Emission of the diesel/CNG Dual-Fuel Combustion Mode in a Stationary CI Engine. Energies, 12, 2019, 1-15. DOI: $10.3390 /$ en 12203857

11. Karago Y., Sandalci T., Koylu U.O., Dalkılıc A.S., Wongwises S. Effect of the use of natural gas-diesel fuel mixture on performance, emissions, and combustion characteristics of a compression ignition engine. Advances in Mechanical Engineering, 2016, 1-13. doi.org/10.1177/1687814016643228

12. Karim G. A., Klat S.R., Moore N.P.W. Knock in dual fuel engines. Proc. Inst. Mech. Engr., 181(1), 1966, 453-466. DOI: 10.1243/PIME_ PROC_1966_181_042_02

13. Longwic R., Sander P., Zdziennicka A., Szymczyk K., Jańczuk B. Combustion Process of Canola Oil and n-Hexane Mixtures in Dynamic Diesel Engine Operating Conditions. Applied Sciences, 10(1), 2020, 1-15. DOI: 10.3390/app10010080

14. Majczak A., Barański G., Siadkowska K., Sochaczewski R. CNG Injector research for dual fuel engine. Advances in Science and Technology Research 11(1), 2017, 212-219. DOI: $10.12913 / 22998624 / 68458$

15. Nieman D.E., Dempsey A.B., Reitz R.D. HeavyDuty RCCI Operation Using Natural gas and Diesel. SAE paper 2012-01-0379, 2012. DOI: $10.4271 / 2012-01-0379$

16. Ogawa H., Miyamoto N., Li C., Nakazawa S. Low Emission and Knock-FreeCombustion with Rich and Lean Biform Mixture in a Dual-Fuel CI Engine with Induced LPG as the Main Fuel. SAE Technical Paper 2001-01-3502, 2001. DOI: 10.4271/2001-01-3502
17. Ogawa H., Zhao P., Kato T., Shibata G. Improvement of Combustion and Emissions in a Dual Fuel Compression Ignition Engine with Natural gas as the Main Fuel. SAE Technical Paper 2015-01-0863, 2015. DOI: $10.4271 / 2015-01-0863$

18. Park H., Shim E., Bae C. Improvement of combustion and emissions with exhaust gas recirculation in a natural gas-diesel dual-fuel premixed charge compression ignition engine at low load operations. Fuel, 235, 2019, 763-774. DOI: 10.1016/j. fuel.2018.08.045

19. Paykani A., Kakaee A.H., Rahnama P., Reitz R.D. Effects of diesel injection strategy on natural gas/ diesel reactivity controlled compression ignition combustion. Energy, 90(1), 2015: 814-826. DOI: 10.1016/j.energy.2015.07.112

20. Różycki, A. Analysis of performance of dual-fuel turbocharged compression ignition engine. Journal of KONES, 17(3), 2010, 393-399.

21. Sayin C., Canakci M. Effects of injection timing on the engine performance and exhaust emissions of a dual-fuel diesel engine. Energy Conversion and Management, 50(1), 2009, 203-213. DOI: 10.1016/j.enconman.2008.06.007

22. Senthilkumar G., Sajin J.B., Yuvarajan D., Arunkumar T. Evaluation of emission, performance and combustion characteristics of dual fuelled research diesel engine. Environmental Technology, 41(6), 2020, 711-718. DOI: 10.1080/09593330.2018.1509888

23. Tomita E., Harada Y., Kawahara N., Sakane A. Effect of EGR on Combustion and Exhaust Emissions in Supercharged Dual-Fuel Natural gas Engine Ignited with Diesel Fuel. SAE Technical Paper 2009-01-1832, 2009. DOI: 10.4271/2009-01-1832

24. Walker N.R., Wissink M.L., Del Vescovo D.A., Reitz R.D. Natural gas for High Load DualFuel Reactivity Controlled Compression Ignition in Heavy-Duty Engines. Journal of Energy Resources Technology, 137(4), 2015. DOI: 10.1115/1.4030110

25. Wei L., Geng P. A review on natural gas/diesel dual fuel combustion, emissions and performance. Fuel Processing Technology, 142, 2016, 264-278. DOI: 10.1016/j.fuproc.2015.09.018

26. Wołoszyn R. Dual fuel turbocharged CI engine equipped with common rail system fuelled with natural gas and diesel fuel. Journal of KONES, 15(4), 2008, 613-620.

27. Selim M.Y.E. Effect of exhaust gas recirculation on some combustion characteristics of dual fuel engine. Energy Conversion and Management, 44(5), 2003, 707-721. DOI: 10.1016/ S0196-8904(02)00083-3 